Tulving E. Concepts of human memory. In: Squire L, Lynch G, Weinberger NM, McGaugh JL (editors). Memory: organization and locus of change. New York: Oxford Univ. Press, 1991.

2. Brandt J, Benedict RHB. Hopkins verbal learning test - revised. Odessa: Psychological Assessment Resource, 2001.

3. Benedict RHB. Brief visuospatial memory test - revised. Odessa:
Psychological Assessment Resource, 1997

4. Brucki S, Nitrini R, Caramelli P, Bertolucci PHF, Okamoto $\mid H$. Sugestões para o uso do mini-exame do estado mental no Brasil. Ara Neuropsiquiatr 2003:61:777-781.

5. Zigmond AS, Snaith RP. The hospital anxiety and depression scale. Acta Psychiatr Scand 1983;67:361-370.

\title{
Reversible parkinsonism associated with neurocysticercosis
}

\author{
Parkinsonismo reversível associado com neurocisticercose \\ Plínio M. G. de Lima, Renato P. Munhoz, Hélio A. G. Teive
}

Movement Disorders Unit, Neurology Service, Internal Medicine Department, Hospital de Clínicas, Federal University of Paraná, Curitiba PR, Brazil.

Correspondence: Hélio A. G. Teive; Rua General Carneiro 1.103 / 102; 80060-150 Curitiba PR - Brasil; E-mail: hagteive@mps.com.br

Conflict of interest: There is no conflict of interest to declare.

Received 23 May 2012; Received in final form 04 June 2012; Accepted 11 June 2012

A 38-year-old female was assessed in a county hospital with a four-month history of severe throbbing morning headaches. Due to the syndromic diagnosis of intracranial hypertension, a brain magnetic resonance imaging (MRI) was performed showing evidence of supratentorial noncommunicating hydrocephalus because of an intraventricular cyst. The cyst was located at the level of the frontal horn of the right lateral ventricle, extending through the foramen of Monro to the third ventricle. Additionally, there were signs of edema in the midbrain periaqueductal region. The patient was treated with a ventriculoperitoneal (VP) shunt, and the symptoms of intracranial hypertension improved. A diagnosis of neurocysticercosis (NCC) was established after analysis of CSF, and positive antibodies reactions were detected. The patient was started on high-dose oral albendazole ( $3.2 \mathrm{~g}$ qd). After four days, additional signs were detected, including mutism, hypomimia, and sialorrhea, associated with severe parkinsonism (marked rigidity, bradykinesia, and resting upper limb tremor). A new brain MRI showed milder hydrocephalus. However, the intraventricular cyst and cerebral aqueduct edema and ependymitis remained unchanged (Figs 1 and 2).

At such point, she was referred to our Service of Neurology at the Hospital de Clínicas, Federal University of Paraná. On admission, neurological examination showed a severe Parkinsonian syndrome that also included marked postural instability, anarthria, and vertical ophthalmoparesis for upward gaze.

Our diagnosis was of Parkinsonism secondary to NCC. We believe that treatment with high-dose albendazole made the presentation worse by adding a reactive inflammatory response and by aggravating ependymitis and tissue damage.
Methylprednisolone pulse therapy was then started ( $1 \mathrm{~g}$ intravenous, daily, for five days). Symptomatic treatment also included levodopa/carbidopa (250/50 mg daily), with progressive improvement in Parkinsonism symptom. Finally, she then underwent endoscopic neurosurgery including monroplasty, removal of the cyst, pellucidoctomy, and third ventriculostomy. Neuropathological examination confirmed the diagnosis of NCC.

Eight months later, the patient was progressively withdrawn from dopaminergic treatment and remained asymptomatic, able to return to her routine activities.

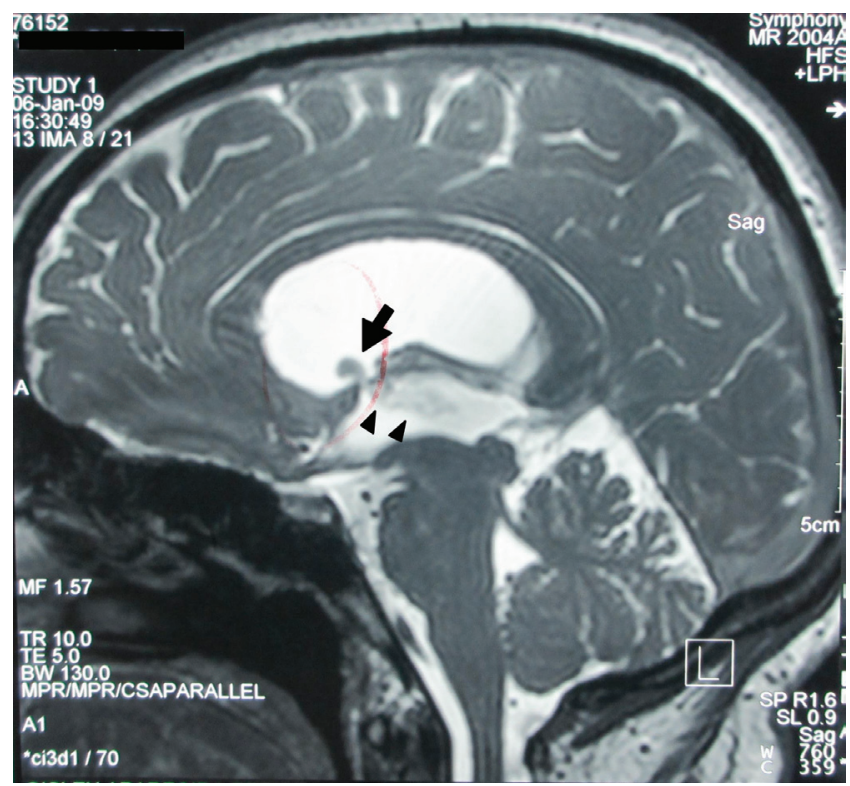

Fig 1. Brain magnetic resonance imaging sagittal T2-weighted image showed an intraventricular cyst (arrow) extending to the third ventricle (arrowheads). 


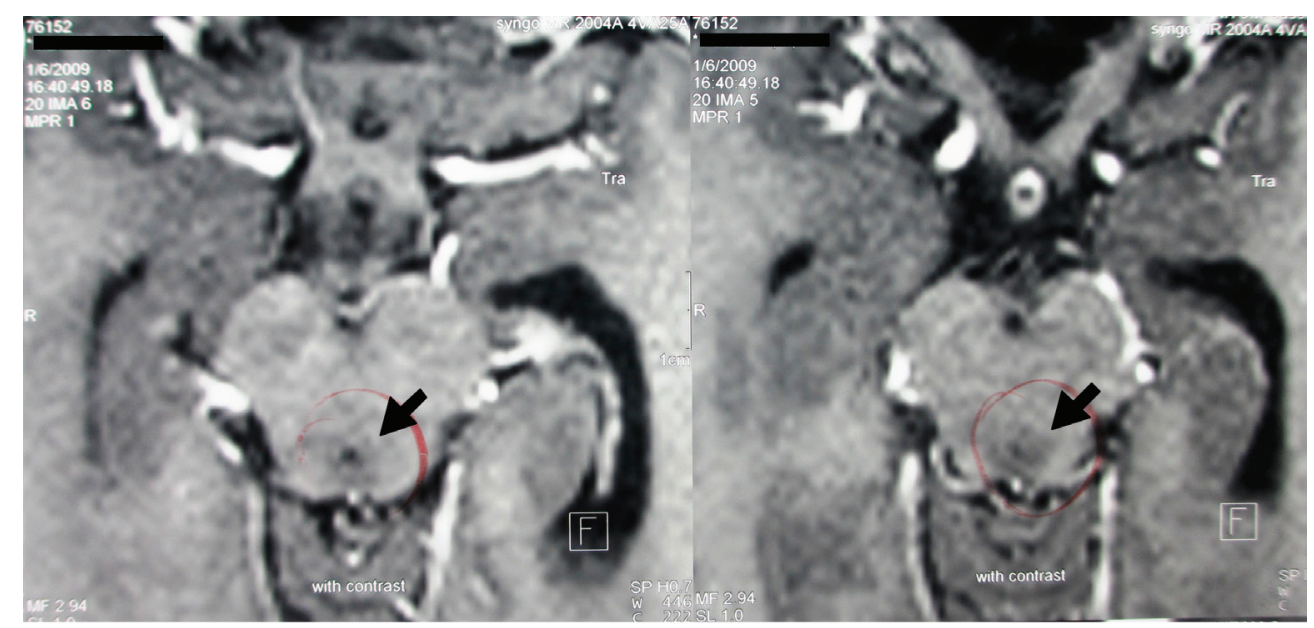

Fig 2. Contrast-enhanced axial T1-weighted image with edema around the cerebral aqueduct (arrows).

This case shows the rare occurrence of Parkinsonism secondary to NCC, leading to hydrocephalus and brainstem ependymitis. NCC is the most common helminth infection of the central nervous system, particularly in developing countries ${ }^{1}$. Parkinsonism secondary to NCC can be related to hydrocephalus secondary to cysts of the fourth ventricle, perimesencephalic cysts, basal racemose cysts and brainstem ependymitis due to the cyst, as well as by ischemic lesions in the midbrain ${ }^{2-4}$.

It was clear from the clinical description that the Parkinsonism symptoms were greatly exacerbated after albendazole treatment was started. This complication has been described in the literature and occurs because cysticidal drugs may lead to an intense inflammatory reaction, especially in forms of NCC involving intraventricular cysts and ependymitis/encephalitis ${ }^{5}$.

Cysticercotic encephalitis should be considered in the differential diagnosis of rapidly progressive Parkinsonism, with atypical features in regions where this infection is common ${ }^{2.3}$. The case presented here resembles others already described, with the peculiarity that there was a deterioration of the symptoms of Parkinsonism after using high-dose albenzadole ${ }^{2-4}$.

\section{References}

1. Takayanagui OM, Jardim E. Clinical aspects of neurocysticercosis: analysis of 500 cases. Arq Neuropsiquiatr 1983;41:50-63.

2. Sá DS, Teive HAG, Troiano AR, Werneck LC. Parkinsonism associated with neurocysticercosis. Parkinsonism Relat Disord 2005;11:69-72.

3. Verma A, Berger JR, Bowen BC, Sanchez-Ramos J. Reversible parkinsonian syndrome complicating cysticercus midbrain encephalitis. Mov Disord 1995;10:215-219.
4. Curran T, Lang AE. Parkinsonism syndromes associated with hydrocephalus: case report, a review of the literature, and pathophysiological hypotheses. Mov Disord 1994;9: 508-520.

5. Garcia HH, Evans CAW, Nash TE, et al. Current consensus guidelines for treatment of neurocysticercosis. Clin Microbiol Rev 2002;15: 747-756. 